\title{
11
}

\section{Media and migration: Comparative analysis of print and online media reporting on migrants and migration in selected countries}

Marie McAuliffe, Warren Weeks and Khalid Koser ${ }^{1}$

By its very nature, international migration is transnational. The movement of people across borders necessarily relates to more than one state, and given the increase in scale and diversity of international migration over recent decades, nearly all countries in the modern era are affected by international migration (Castles, de Haas, \& Miller, 2014). Some countries, including some of those within the scope of this project, are affected by migration significantly, both positively and at times negatively. Immigration has become a first order public policy issue in many countries in the world.

It is unsurprising, then, that the topic of international migration is often included in public opinion surveys, although arguably the political significance of migration often outweighs its numerical significance. Analysis of print and online media in the UK, for example, has shown that the substantial political interest in this complex public policy topic can be put in a somewhat different perspective by examining overall

\footnotetext{
1 The authors are grateful for research assistance from Simone Gangell and Adam Palmer in the preparation of this chapter.
} 
media coverage by themes. Content analysis undertaken as part of this study found that migration-related media coverage in the UK accounted for around 2-3 per cent of total coverage compared to, for example, sport (24-30 per cent), the economy (19-20 per cent), science/health (8-10 per cent) and climate change (1-2 per cent).

How migrants and migration are covered in the media matters for at least three reasons. First, although the chain of causality and the distinctions between causes and consequence is complex, there is a general acceptance that the media can influence, and be influenced by, popular opinion and political agendas. Thus, media coverage may be a barometer for political and public attitudes towards migration, and in turn shape these attitudes. Second, media coverage is likely to influence the perceptions of migrants themselves in society, for example, regarding to what extent they perceive migrants to be widely accepted or excluded, to be fairly represented, or to be scapegoated. Third, it is possible, given global access to much media, that media coverage may also influence the decision-making of migrants considering whether to move to particular destination countries.

Against this backdrop, the purpose of this research is to analyse in more depth how the media covers migrants and migration. More specifically, the purpose of this research is to compare media discourses on migrants and migration in selected countries by examining thematic content, contextual framing and the extent of polarisation of messages communicated via print and online media over two six-month periods.

\section{Research questions and scope}

The objective of the media and migration research project was to create baseline analyses of media coverage of migration and migrants in 13 selected countries for two six-month study periods on:

- the thematic content of print and online media messages;

- the extent to which that coverage was favourable, unfavourable or neutral;

- the high-level contextual framing in which migration messages were reported. 
We analysed media messaging within two sets of print and online media pieces for the 13 selected countries during two six-month periods (1 October, 2013 to 31 March, 2014; and 1 April, 2014 to 30 September, 2014), which are referred to as Phase I and Phase II throughout this chapter. The 13 countries in scope have been categorised as either 'very high human development (HD)' countries or 'other HD' countries. ${ }^{2}$ This has been done for several reasons. First, one of the key findings from Phase I of the project was that characterising countries as either 'destination' or 'origin' countries for migration purposes was found to be overly simplistic given the range of migration issues they may face. Pakistan, for example, is a significant destination and origin country as well as a transit country and the world's largest host country of refugees. It could be argued that at least one of the additional countries included in this phase (Thailand) is perhaps more of a transit country for irregular migration than a destination or origin country, further complicating a destination-origin typology. Second, the application of the Human Development Index (HDI) has been chosen because it incorporates a number of elements, including Gross National Income (GNI) per capita at purchasing power parity (PPP), life expectancy and mean and expected years of schooling, so is more than just an economic indicator. In addition, the HDI is reasonably long-standing, widely accepted and UN-supported. Third, the HDI has been found to correlate with international migration flows (Kandemir, 2012), and so it is arguably one of the least worst bases from which to develop a dichotomous categorisation to analyse media and migration coverage in multiple countries. That said, any and all such categorisations are generally applied only to ensure high-level analysis is as accessible and digestible as possible. Individual country reports are also provided, to supplement the high-level analysis.

The six 'very high HD' countries in scope are Australia, Canada, the Netherlands, Norway, Switzerland, and the UK. The seven 'other HD' countries are Afghanistan, Bangladesh, Malaysia, Pakistan, Sri Lanka, Thailand and Vietnam. Within these two types, a mix of countries was included, both from a geographic perspective and from a migration perspective (e.g. regular/irregular migration, asylum-refugee/labour/ student migration). The three countries that were added for Phase II were Australia, Malaysia and Thailand, which were considered to be of particular interest to the Research Program.

2 These categories are based on United Nations Development Programme (2014). 
Table 11.1: Human Development Index rankings and groupings of selected countries in scope, 2014

\begin{tabular}{|l|l|l|}
\hline Country & Ranking (187 countries) & HDI group \\
\hline Norway & 1 & Very high HD \\
\hline Australia & 2 & Very high HD \\
\hline Switzerland & 3 & Very high HD \\
\hline Netherlands & 4 & Very high HD \\
\hline Canada & 8 & Very high HD \\
\hline United Kingdom & 14 & Very high HD \\
\hline Malaysia & 62 & High HD \\
\hline Sri Lanka & 73 & High HD \\
\hline Thailand & 89 & High HD \\
\hline Vietnam & 121 & Medium HD \\
\hline Bangladesh & 142 & Medium HD \\
\hline Pakistan & 146 & Low HD \\
\hline Afghanistan & 169 & Low HD \\
\hline
\end{tabular}

Source: United Nations Development Programme (2014).

Content from both print and online sources was obtained from commercial media content suppliers or the publishers' archives. Broadcast media content was generally outside the scope of the project, partly because of the prohibitive cost involved in sourcing such material retrospectively. The exclusion of broadcast material necessarily poses limitations on the analysis. This limitation is potentially more of an issue for some of the non-industrialised country analyses, given literacy and access issues within those countries. Radio broadcasting, for example, is a particularly important form of media in Afghanistan, with its patchy literacy, poor infrastructure and low incomes levels.

Advances in journalism and digital media, however, have led to the converging of news organisations, where news is more commonly published across a multitude of media platforms (Quandt \& Singer, 2009; Erdal, 2009). Research has also indicated that there are no significant differences in news coverage across the different platforms; rather, the main differences are between the types of news organisations and in particular the extent to which they use emotive language (Semetko \& Valenburg, 2000; Keith, Schwalbe, \& Silcock, 2010). 
Social media was also generally outside the scope of this project, primarily due to feasibility. Including broadcast and social media messages would have enabled a more complete comparative analysis. However, while broadcast media is a widely accepted form of mass media in all countries, and could have been included (if feasible cost-wise), including social media would arguably have posed methodological concerns. The extent of social media coverage remains highly variable (Kohut et al., 2012; International Telecommunication Union, 2013), with substantial differences within and between countries. This is less so for print and online media coverage. As a result, comparative analysis of messaging in print and online media was considered the most reasonable approach. Further research on broadcast media would likely shed new light on aspects of the portrayal of migration in the media, but the initial findings from this study of online and print media are still relevant for both very high HD and less developed countries. With growing use of social media in some locations, this is an area that would benefit from targeted mixed methods research in the future.

It is important to note the very different contexts in which media reporting and messaging operates, including in relation to economic, political, social and security-related regulatory environments. These potential differences can include linguistic/sociocultural tendencies towards expression, such that the same story is likely to be expressed using more emotive language in Italy than in Germany, for example. In addition, the results are likely to reflect differences in the proportion of opinion-based coverage versus traditional fact-based journalism. For example, the UK media continues to publish higher proportions of pieces containing opinion compared to media in many other countries.

Of particular relevance to this project was the extent to which the media is free to report news and current affairs. Reporters Without Borders (Reporters Sans Frontiéres, RSF) publishes an annual World press freedom index that measures the level of freedom of information in 180 countries and ranks them accordingly. Final scores for each country range from 0 to 180 (with 0 representing the greatest degree of press freedom of the countries evaluated and 180 representing the lowest) and are based on measurements of plurality, media independence, environment and selfcensorship, legislative framework, transparency, infrastructure and the level of violence against reporters during the study period. 
Table 11.2 shows the 2014 ranking for each country in scope as well as their corresponding ranking by RSF as either 'good situation', 'satisfactory situation', 'noticeable problems', 'difficult situation' or 'very serious situation'.

Table 11.2: World press freedom index ratings and rankings, 2014

\begin{tabular}{|l|l|l|}
\hline Country & Ranking (of 180 countries) & Rating \\
\hline Netherlands & 2 & Good situation \\
\hline Norway & 3 & Good situation \\
\hline Switzerland & 15 & Good situation \\
\hline Canada & 18 & Good situation \\
\hline Australia & 28 & Good situation \\
\hline United Kingdom & 33 & Satisfactory situation \\
\hline Afghanistan & 128 & Difficult situation \\
\hline Thailand & 130 & Difficult situation \\
\hline Bangladesh & 146 & Difficult situation \\
\hline Malaysia & 147 & Difficult situation \\
\hline Pakistan & 158 & Difficult situation \\
\hline Sri Lanka & 165 & Very serious situation \\
\hline Vietnam & 174 & Very serious situation \\
\hline
\end{tabular}

Source: Reporters Without Borders (2014).

Along with issues associated with press freedom, the results of the research need to be viewed within a range of other contexts, including economic, political, security and social—all of which are intrinsically linked to human displacement and migration. These different contexts feed into migration-related articles in the media.

\section{Research method}

The methodology for this project relied on a combination of qualitative content analysis of media articles in representative country-specific sample sets and quantitative modelling. The content analysis was undertaken by multilingual analysts working in both the original (published) language and English. The quantitative component involved the application of a sophisticated human cognitive modelling method able to deal with very large volumes of media articles. 
It was important to begin with the most complete media dataset possible-within the cost, time and feasibility limitations-so that a reasonably precise, sizeable and representative sample of topic-specific media articles for each country could be developed. Refining the country samples involved a 'top-down' analytical approach based on iteratively designing, testing and fine-tuning search strings based on human analysis. The first stage involved multilingual analysts examining media material in its published language-English, Bengali, Dutch, Farsi, French, German, Malay, Dari, Norwegian, Thai, Urdu, Vietnamese, Sinhalese or Tamilbefore being interpreted and stored in English for further analysis.

The methodology also relied on substantial quality assurance and data verification processes throughout the data collection, sorting and analysis phases. A detailed discussion of the methodology is contained in McAuliffe and Weeks (2015).

No allowance was made for significant in-country events, such as general, local or regional elections, which inevitably affected the analysis. The main reason for this limitation was the significant methodological complication required to account for a multitude of in-country events that may affect results, such as elections, economic/financial shocks, natural disasters or terrorist events. In addition, the creation of time series data is assisted by maintaining a consistent approach across all study periods, including as more countries are added to the scope.

A series of country-specific datasets capturing migration-specific themes published in the media during the two six-month research periods was produced. The focal piece country datasets ranged in size from 20,000 pieces (Australia) to 500 (Bangladesh), while the country datasets used for in-depth analysis ranged in size from 1,400 pieces (Switzerland and Canada) to 500 (Bangladesh).

It is important to note the potential for seasonal effects during the two six-month study periods. For example, there was a tendency in very high HD countries for coverage on migration-related issues overall to drop during the Christmas/New Year period. Likewise, the volume of reporting of irregular maritime migration is related to activity, which can involve 'sailing seasons' in some parts of the world (McAuliffe \& Mence, 2014), and reporting of overseas student issues can be related to seasonal student application, acceptance and/or departure times. To overcome some of the potential seasonal effects, future phases would be best undertaken on an annual basis. 


\section{Analytical framework}

The country-specific in-depth analysis sets were analysed to determine thematic content, the tone of the media messaging (favourableneutral-unfavourable), and how messages were contextually framed (humanitarian, sociocultural, economic and/or security). This analytical framework has been replicated from Phase I, and is discussed in detail in McAuliffe and Weeks (2015). By way of a summary, the three analytical frames employed are:

- examination of thematic content under headings that emerged from multiple rounds of analysis in Phase I: 'asylum seekers and refugees', 'emigration and emigrants', 'immigration and immigrants', 'irregular migration', 'migrant accommodation (including detention)', 'overseas students', 'overseas workers' and 'people smuggling and trafficking';

- analysis of message tone as either favourable, unfavourable or neutral, with fact-based reporting being generally neutral and messages containing opinion being generally assessed as 'favourable' or unfavourable';

- analysis of message context using a contextual-associative typology that comprised 'sociocultural', 'economic', 'humanitarian' and 'security' contexts.

Key findings are reported by variables including study period, country, theme, 'favourability', and contextual framing. This can sometimes result in small subsamples being analysed. To ensure the veracity of the research, findings based on subsamples of less than 50 messages (very high HD countries) and 30 messages (other HD countries) are not reported. It is also important to note that quantitative analysis is based on messages rather than articles.

\section{Key findings}

The key findings of the research presented in this paper focus primarily on comparative analysis across the two study periods. From the two phases of research, it is becoming clearer that the media discussion on migration in very high $\mathrm{HD}$ countries tends to contain more in-depth analysis compared to other HD countries, which was more likely to have been driven by specific events and so tended to be more sporadic. 
Taking into account all print and online messages on migration and migrants in all countries, it is evident that there was a small but noticeable shift in message tone between Phases I and II toward a more balanced overall coverage. Favourable messages increased marginally and unfavourable coverage decreased. Despite the slight shift, reporting in Phase II was again largely assessed as being neutral. However, where it was not neutral, reporting was more likely to be unfavourable than favourable. Some themes were more likely to be reported unfavourably (e.g. 'people smuggling and trafficking' in all countries, 'irregular migration' in other HD countries and 'immigration and immigrants' in very high HD countries).

One striking finding of the research was that messaging on migration and migrants in print and online media was predominantly depicted through a 'humanitarian' lens. 'Humanitarian' framing dominated in all countries in scope across Phase II-a change from Phase I, which saw some very high HD countries experience more 'economic' framing. Media reporting tended to be framed in a border/national security context where it related to irregular migration or people smuggling and trafficking.

Each country had its own particular set of migration issues being discussed in print and online media, and it was slightly clearer from the comparisons between the two phases that these migration issues can be linked to a range of broader discussions, including those associated with factors such as political cycles and processes. The changes in Switzerland and the UK's reporting, for example, would appear to be related to elections/ referendums.

\section{Key findings and comparisons - very high HD countries}

The key findings from the analysis of the very high HD country datasets highlight a range of similarities and some differences across the selected group as well as some changes between the phases.

Consistent with Phase I findings, there was a reasonable level of convergence found in very high HD countries of media coverage on migration that does not exist to the same extent for other HD countries studied. This possibly reflects similarities in terms of their migration circumstances and issues. 
The volume of migration-specific print and online messaging increased in Phase II for all countries, which appears to be due in part to the heightened coverage of 'asylum seekers and refugees' and/or 'irregular migration'.

Taking into account all print and online messages on migration and migrants in the very high $\mathrm{HD}$ countries, ${ }^{3}$ it is evident that there was a small but noticeable shift in message tone between Phases I and II toward more balanced coverage. While neutral coverage remained the same, favourable messages increased marginally and unfavourable coverage decreased. Notwithstanding the small but positive shift, coverage of migration in print and online media remained more polarised than in other HD countries, with less neutral reporting and more unfavourable reporting.

The limited extent of favourable messaging on migration across all very high $\mathrm{HD}$ countries is one of the starker findings. Unfavourable coverage significantly outweighed favourable messages. Very high rates of unfavourable messaging were experienced consistently for coverage on 'people smuggling and trafficking', followed by 'irregular migration'.

In terms of contextual framing of all messages, there were noticeable shifts between the two phases, with increases in 'humanitarian' framing and reductions in 'economic' and 'security' framing. This was almost certainly related to the increase in coverage on 'asylum seekers and refugees' (both proportionally and numerically) during Phase II.

\section{Thematic content in print and online media in very high HD countries}

All media messages from the country-specific datasets were analysed against a number of themes. A single print or online article may contain more than one message, and each message may relate to more than one theme. Analysing the datasets in this way allows for all messages to be accounted for in thematic terms.

As shown in Figure 11.1, the volume of migration-specific print and online messaging increased in Phase II for all countries. While the increases may be related to seasonal effects, they are clearly due in part to the heightened

3 Involved analysis of more than 77,000 individual messages from 7,500 articles reported between 1 October, 2013 and 30 September, 2014 in Australia, Canada, the Netherlands, Norway, Switzerland and the UK. 
coverage of 'asylum seekers and refugees' and/or 'irregular migration', which increased in both actual and proportional terms in all countries between the two study periods.

The increase was related to ongoing coverage of mass displacement in key parts of the world, such as Syria, as well as the large maritime flows of asylum seekers and refugees in the Mediterranean Sea and Italy's Mare Nostrum operational response. Some countries, such as Switzerland, also saw increased coverage of integration of asylum seekers and refugees.

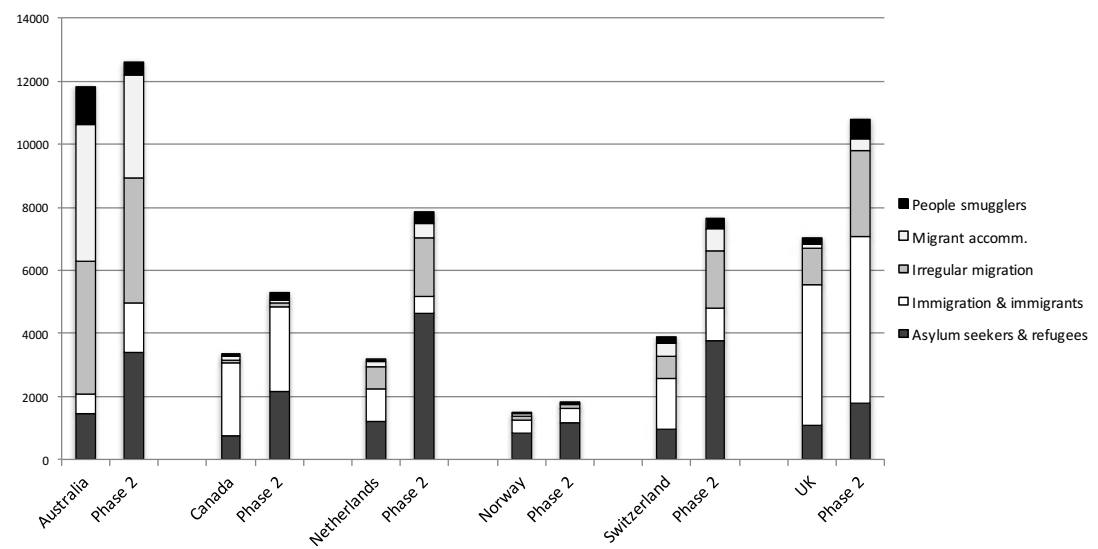

Figure 11.1: Thematic coverage of migration in print and online media in selected very high HD countries by volume-key migration themes: Phase I and II

Notes: Messages: Australia $(n=24,428)$, Canada $(n=8,629)$, Netherlands $(n=11,023)$, Norway $(n=3,327)$, Switzerland $(n=11,538)$, UK $(n=17,840)$. Articles: Australia $(n=13,256)$, Canada $(n=5,640)$, Netherlands $(n=4,337)$, Norway $(n=1,364)$, Switzerland $(n=4,875)$, UK $(n=8,360)$.

When the messaging is analysed on a proportional basis, as illustrated in Figure 11.2, one of the first things to note is that countries experienced quite distinctive media coverage of migration themes. Outside of the theme 'people smugglers' (which was uniformly low in proportional terms, at 10 per cent or less in all countries), there was variation of themes proportionally in all six very high $\mathrm{HD}$ countries. Australia was the only country that experienced significant coverage of migrant accommodation, which was related largely to asylum seeker processing centres in Papua New Guinea and Nauru. Canada and the UK appeared to have a more 
generalised media discussion, largely focused on the broad theme of 'immigration and immigrants', while Norway's media coverage in both phases was dominated by the 'asylum seekers and refugees' theme.

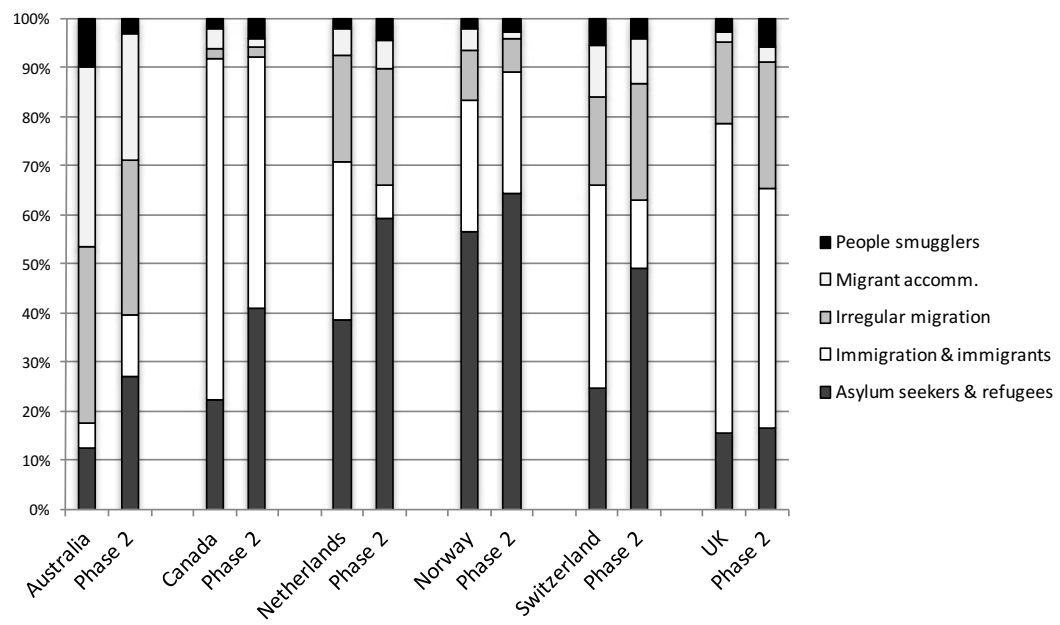

Figure 11.2: Thematic coverage of migration in print and online media in selected very high HD countries by proportion-key migration themes: Phase I and II

Notes: Messages: Australia $(n=24,428)$, Canada $(n=8,629)$, Netherlands $(n=11,023)$, Norway $(n=3,327)$, Switzerland $(n=11,538)$, UK $(n=17,840)$. Articles: Australia $(n=13,256)$, Canada $(n=5,640)$, Netherlands $(n=4,337)$, Norway $(n=1,364)$, Switzerland $(n=4,875)$, UK $(n=8,360)$.

The other striking aspect of the data is that between the two study periods, thematic coverage was reasonably consistent proportionally. As shown in Figure 11.2, this was particularly noticeable for the UK, Norway and to a lesser extent Canada, with all showing little variation.

Several countries experienced significantly reduced coverage of the theme 'immigration and immigrants', most notably the Netherlands and Switzerland. In Switzerland's case, this related to the February 2014 national referendum 'against mass immigration', reporting of which was included in the 'immigration and immigrants' theme during Phase I. A 30 November, 2014 Swiss national referendum on limiting immigration was rejected, and coverage in the lead-up to the vote almost certainly occurred outside the Phase II study period (which ended on 30 September). 
In the UK...

'Immigration and immigrants' was the most prominent theme across the 12-month period, accounting for 45 per cent of all local focal stories. It was most prominent in Phase I of the study, when more than half of all coverage focused on this issue. It was again the dominant theme for the second study period, accounting for around half of all focal stories.

The late-February, 2014 release of figures showing a rise of more than 30 per cent in net migration, to 212,000 over the year to September 2013, was seen in many quarters as evidence the government had failed to meet its pledge to bring net migration to below 100,000 . In late July, calls for tougher restrictions on migrant benefits became more prominent after Prime Minister David Cameron proposed new policies.

\section{Extent of polarisation of print and online media content in very high HD countries}

Much has been written about the polarisation, and the perceived increasing polarisation, of the public discourse on migration in destination countries (International Organization for Migration [IOM], 2011a; Koser, 2012; Koser, 2014). The discourse has variously been described as 'toxic', 'unbalanced' and 'extreme' (IOM, 2011a; Koser, 2012).

To a significant extent, this research supports those views and findings. However, as was the case with Phase I, this phase has again found that there is considerable variation in the extent of polarisation when examined by specific themes. In addition, there is also variability between countries. More importantly, however, when all messages related to migration and migrants are aggregated across all very high HD countries, an interesting picture emerges. It is evident that there was a small but noticeable shift between Phases I and II for the better in terms of overall balance. Overall, and as can be seen from Figure 11.3, neutral coverage remained the same (40 per cent) while favourable coverage increased (from 14 per cent to 17 per cent) and unfavourable coverage decreased (from 46 per cent to 43 per cent). It would appear that no specific events or circumstances drove this change-it is more likely that a combination of changes in overall message volume in some countries (e.g. Switzerland and the Netherlands), together with variations in thematic content, appears to have overall had a combined effect. It will be interesting to examine this high-level indicator in future phases, particularly as it tends to blunt the more event-based changes, and has the ability to provide a useful overall barometer on print and online media coverage of migration and migrants. 


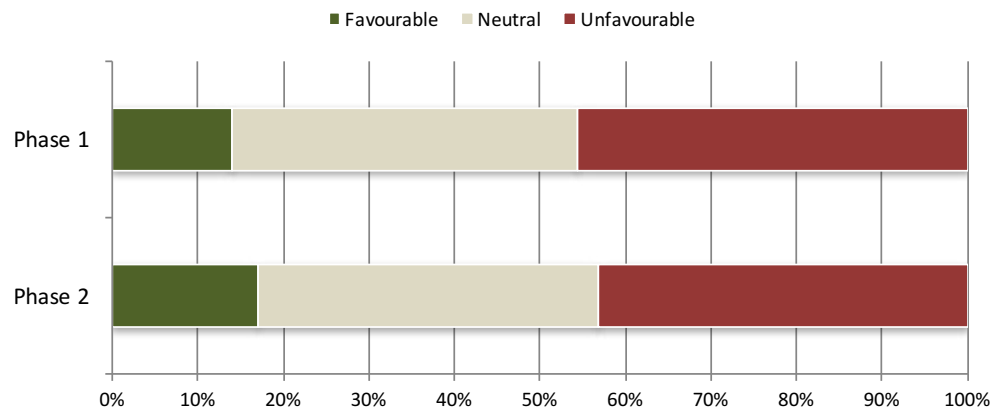

Figure 11.3: Favourable-neutral-unfavourable coverage of migration in print and online media in selected very high HD countries combinedall migration themes: Phase I and II

Notes: Messages: Phase $1(n=31,064)$, Phase $\|(n=46,552)$. Articles: Phase $1(n=16,226)$, Phase II ( $n=22,189)$.

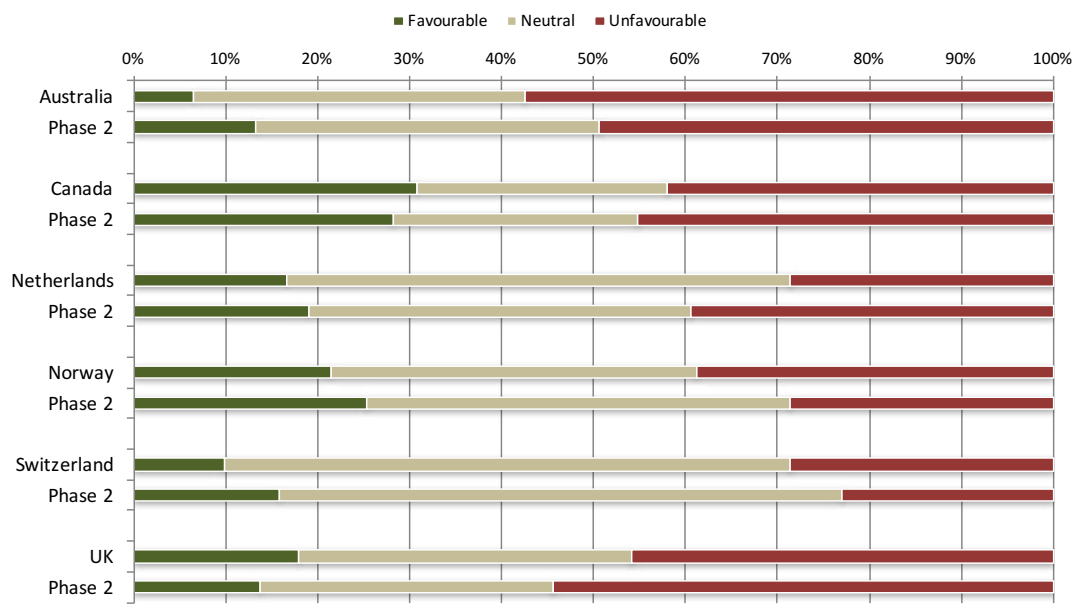

Figure 11.4: Favourable-neutral-unfavourable coverage of migration in print and online media in selected very high HD countries by countryall migration themes: Phase I and II

Notes: Messages: Australia $(n=24,428)$, Canada $(n=8,751)$, Netherlands $(n=11,080)$, Norway $(n=3,345)$, Switzerland $(n=11,628)$, UK $(n=18,385)$. Articles: Australia $(n=13,256)$, Canada $(n=5,738)$, Netherlands $(n=4,364)$, Norway $(n=1,371)$, Switzerland $(n=4,940)$, UK $(n=8,745)$.

Despite the shift toward slightly more balanced coverage between the two phases, it is clear from both Figures 11.3 and 11.4 that there is less favourable messaging than unfavourable messaging on migration and migrants in print and online media across all selected very high HD countries. This is one of the more striking findings, including because 
it holds true for both study periods. In all countries for both phases, unfavourable messages significantly outweighed favourable messages. Figure 11.5 also shows that for both study periods, Australia and the UK had the highest proportion of unfavourable messaging of migration issues (ranging between 46 and 57 per cent). Australia also experienced the lowest favourable coverage of all countries.

\begin{abstract}
In Switzerland ...
In December 2013, the media landscape was dominated by four stories: the Swiss People's Party (SVP) initiative to cut mass immigration, conditions in the Lampedusa Island refugee camps, irregular immigrants arriving in the Spanish enclaves of Morocco and debates in the UK about migrant worker access to benefits.

The SVP initiative remained a prominent story in January, with a focus on seasona workers, the economy and social welfare. There was also discussion relating to Swiss support for Syrian refugees. Coverage spiked in February 2014, as the SVP initiative against mass migration was accepted by referendum. Much of this coverage consisted of short bulletin-type reports.
\end{abstract}

Canada again experienced the most polarised coverage, with the lowest neutral coverage (27 per cent), the highest favourable coverage ( 28 per cent) and the third highest unfavourable coverage ( 45 per cent). Switzerland, on the other hand, again experienced the least polarised coverage of aggregate migration messaging, with the highest neutral coverage (61 per cent). Switzerland and Norway both experienced shifts in tone of coverage, with slightly higher proportions of favourable messaging and slightly lower proportions of unfavourable messaging between the two study periods.

Overall, the consistency between the results for the two study periods is notable, particularly for the proportions of favourable messaging. The consistency occurred despite the changes in overall volume (Figure 11.1) and applied to both Switzerland and the UK, whose citizens went to the polls in or very near Phase I. It would be very interesting to examine the proportions of favourable messaging over time. In relation to specific themes - the most prominent being immigration and immigrants', 'irregular migration' and 'asylum seekers and refugees'there was noticeable variability among the very high HD countries and compared with the aggregate results for all migration content. 


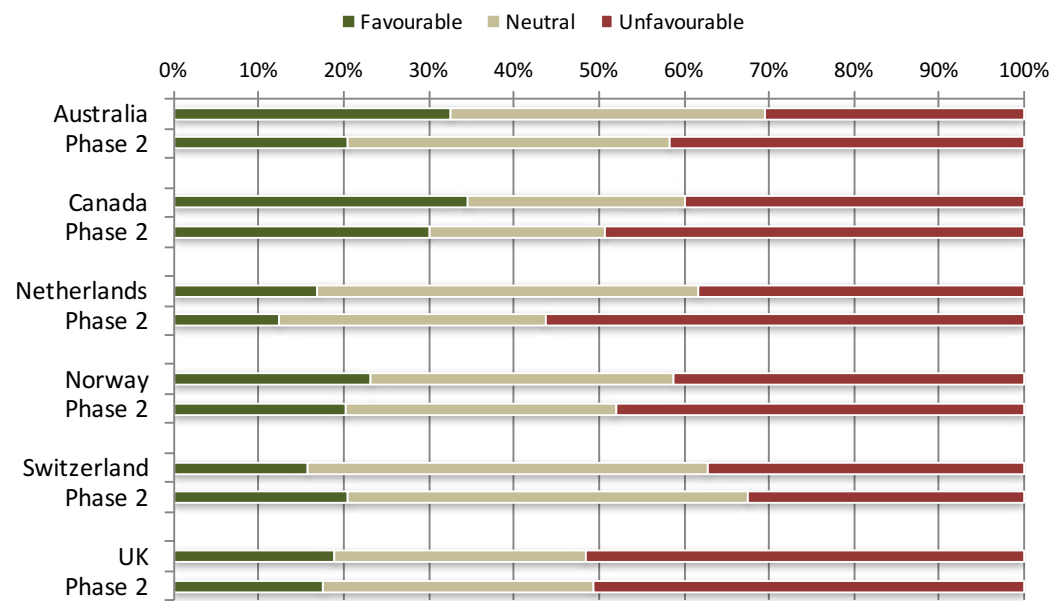

Figure 11.5: Favourable-neutral-unfavourable coverage of migration in print and online media in selected very high HD countries-immigration and immigrants theme: Phase I and II

Notes: Messages: Australia $(n=2,188)$, Canada $(n=5,017)$, Netherlands $(n=1,543)$, Norway $(n=853)$, Switzerland $(n=2,660)$, UK ( $n=9,720)$. Articles: Australia $(n=996)$, Canada $(n=2,555)$, Netherlands $(n=676)$, Norway ( $n=313)$, Switzerland $(n=980)$, UK $(n=3,920)$.

The UK and the Netherlands experienced the highest proportion of unfavourable coverage on 'immigration and immigrants', as shown in Figure 11.6, with Canada again having had the highest proportion of favourable coverage, as well as the most polarised coverage. As with the aggregate results, all countries experienced more unfavourable than favourable coverage.

It is also interesting to note that despite 'immigration and immigrants' being the least polarised theme across the five countries, it was again the most polarised theme within the Swiss context. That said, there was a slightly positive shift in Switzerland in Phase II, which ended just prior to the November 2014 failed referendum on reducing immigration quotas. The Netherlands, on the other hand, witnessed a shift between the two phases, which appears to have been related to discussion of the potential links between migration and social disharmony as well as the employment market. In Australia, 'immigration and immigrants' received the highest proportions of favourable messaging of all themes, notwithstanding the drop in Phase II. 
Media on 'irregular migration' showed increased unfavourable messaging across most very high HD countries. Australia, Canada and the UK all had more than half of all messaging on 'irregular migration' as being unfavourable, which was in contrast to the mainland European countries. It is, however, important to note that Canada and Norway experienced very low volumes of coverage on this theme. Australia recorded no favourable messaging on 'irregular migration', noting that proportions of favourable messaging were very low for Phase II across all countries.

There was also noticeable variability between Phase I and II in most of the countries (Australia, Canada, Norway and the UK), with Switzerland and the Netherlands remaining fairly constant. Australia was the only country that experienced a discernible positive shift in coverage tone, becoming more positive in Phase II, which is likely to be related to the much-reduced volume and tempo of coverage associated with irregular maritime arrivals (IMAs) — no IMAs reached Australia during Phase II. In contrast, Canada, Norway and the UK's coverage contained much higher proportions of unfavourable coverage.

\footnotetext{
In Australia ...

During the 12-month period from October 2013 to September 2014, Australia's media outlets published the second largest volume of material, second only to the UK. The Australian public received a constant background hum of migration-related messages. From this ocean of material, coverage of particular events would periodically rise, attain prominence for a time, then recede, to be replaced by the next hot item. Messages, in the form of both news and opinion relating to migration events, often appeared in media outlets across the country-their audience footprints enlarged by syndication across online media networks.

In the context of Australian reporting of issues associated with IMAs, the related themes of 'irregular migration', 'migrant accommodation' (including detention), 'asylum seekers and refugees' and 'people smuggling and trafficking' together accounted for 93 per cent of all coverage.
}

In contrast to 'irregular migration', the theme 'asylum seekers and refugees' received more favourable messaging in most countries, with positive shifts occurring in Switzerland, Canada and Norway (as shown in Figure 11.7). Interestingly, Australia experienced the lowest levels of unfavourable messaging on this theme, which was in stark contrast to messaging on 'irregular migration'. 


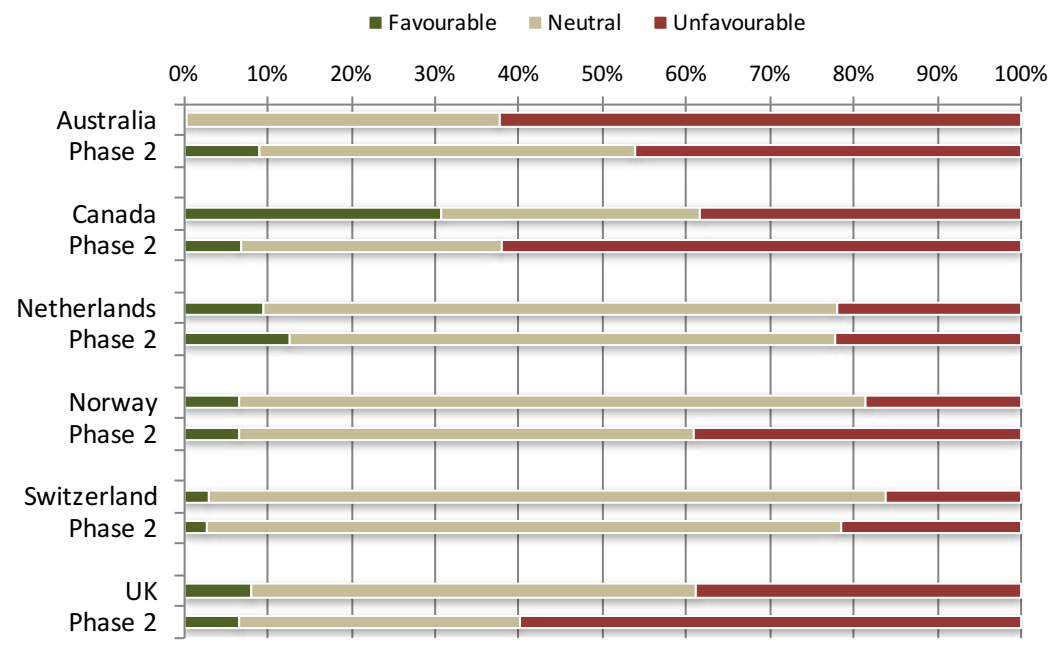

Figure 11.6: Favourable-neutral-unfavourable coverage of migration in print and online media in selected very high HD countries-irregular migration theme: Phase I and II

Notes: Messages: Australia $(n=8,210)$, Canada $(n=181)$, Netherlands $(n=2,566)$, Norway $(n=273)$, Switzerland $(n=2,498), \cup K(n=3,925)$. Articles: Australia $(n=4,350)$, Canada $(n=148)$, Netherlands ( $n=793)$, Norway $(n=137)$, Switzerland $(n=1,108)$, UK $(n=1,800)$.

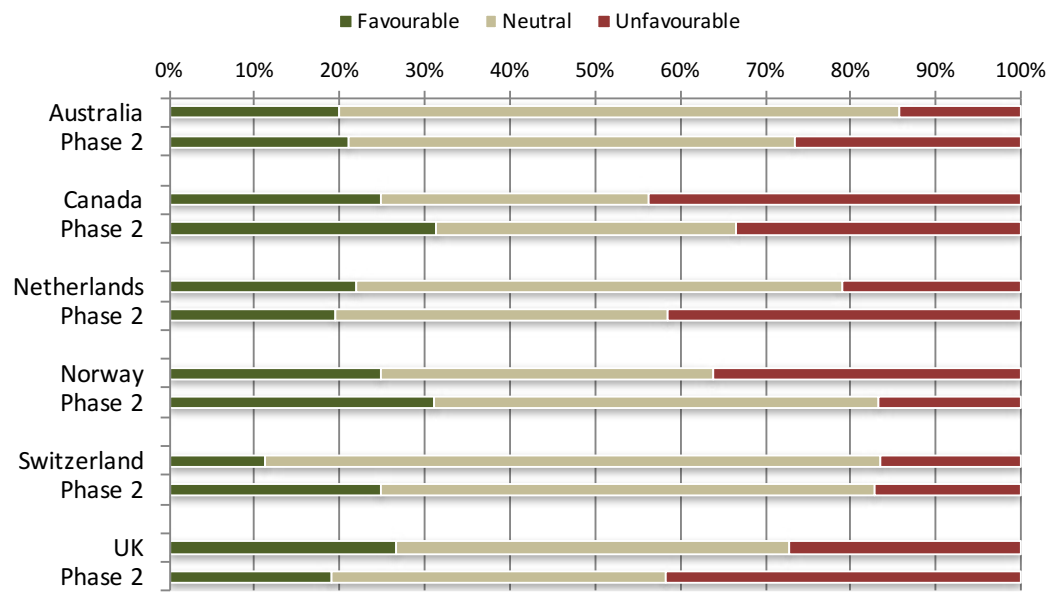

Figure 11.7: Favourable-neutral-unfavourable coverage of migration in print and online media in selected very high HD countries-asylum seekers and refugees theme: Phase I and II

Notes: Messages: Australia $(n=4,850)$, Canada $(n=2,913)$, Netherlands $(n=5,871)$, Norway $(n=2,021)$, Switzerland $(n=4,718)$, UK $(n=2,880)$. Articles: Australia $(n=2,860)$, Canada $(n=2,637)$, Netherlands $(n=2,516)$, Norway $(n=785)$, Switzerland $(n=1,808)$, UK $(n=1,700)$. 
The Netherlands saw a notable increase in unfavourable messaging on this theme. This related largely to criticism of the government's handling of asylum seeker and refugee issues, including refugee intake numbers, accommodation and child pardon policies.

Overall, and as was seen during Phase I, there are substantial differences between countries on the extent of polarisation of media messaging on migration and migrants. Switzerland again exhibited a more nuanced discussion of migration and migrants as well as a much less polarised discussion. Canada's print and online media messaging was generally the most polarised overall; however, Australia and the UK experienced very high proportions of unfavourable messaging (and low or no favourable messaging) on specific themes. Overall, Australia experienced the most unbalanced overall discussion on migration and migrants in both phases.

\section{Framing of the media discourse in very high HD countries}

As well as grouping messages into thematic sets to facilitate the quantitative assessment of media across the countries in this study, we also analysed media content according to a contextual-associative typology. This enabled critical examination and reporting on the overall context in which various propositions and/or themes were couched.

Overall, and as shown in Figure 11.8, the research found that migration coverage in Phase II was more likely to have been discussed in a 'humanitarian' context in all countries, with very high proportions across all countries (ranging from 57 per cent in the UK to 74 per cent in the Netherlands). This appears to correlate to the increase in the 'asylum seekers and refugees' theme across all countries (see Figure 11.1). In contrast, the 'security' context dropped or remained the same across all countries, although was still noticeably larger proportionally in Australia compared to elsewhere (at 17 per cent). The 'economic' framing also dropped in most countries but most dramatically in the UK (from 53 per cent to 20 per cent).

At the aggregate level, and taking into account all media messages from all six very high HD country datasets, the variability between countries apparent in Phase I was not found in Phase II. All very high HD countries experienced notable uniformity in the framing of all media messaging in Phase II, which may be related to the increase in proportional and actual terms of coverage of 'asylum seekers and refugees'. 


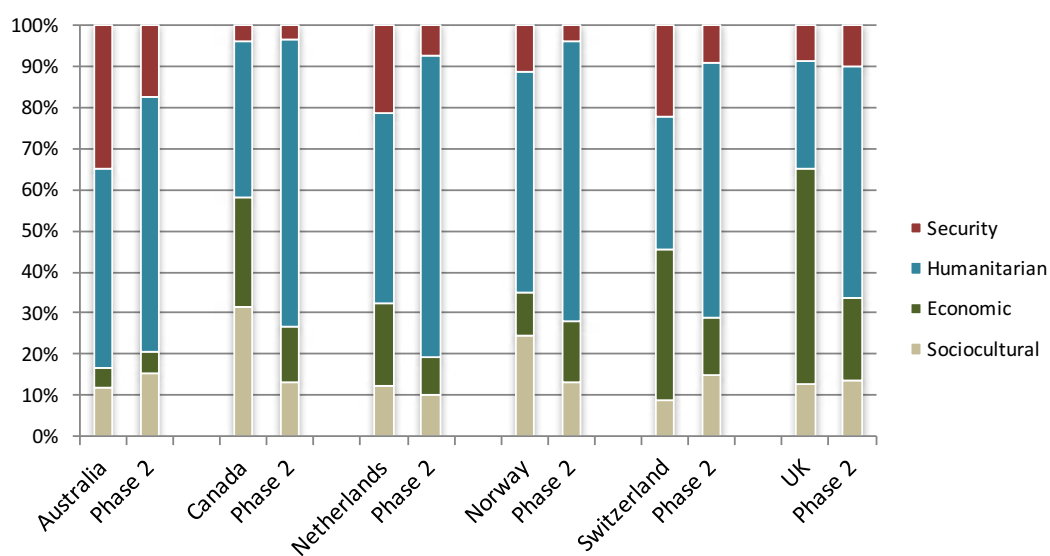

Figure 11.8: Framing of migration messages in print and online media in selected very high HD countries-all migration themes, October 2013 to March 2014

Notes: Messages: Australia ( $n=23,739)$, Canada $(n=8,397)$, Netherlands $(n=10,895)$, Norway $(n=3,249)$, Switzerland $(n=11,313)$, UK $(n=17,715)$.

In the UK and Switzerland, it does appear that migration was part of broader economic and political discussions during Phase I, particularly in the lead-up to the UK local elections (May 2014) and the Swiss referendum on immigration quotas (February 2014). Both countries experienced substantial reductions in the 'economic' framing of messaging in Phase II, and so were more in line with the other countries.

In Norway ...

The 'asylum seeker and refugee' theme captured the greatest share of coverage, accounting for 57 per cent of all the messages tracked.

This was also the only theme for which favourable commentary outstripped the unfavourable - although this only happened in the latter part of the study, as negative issues covered in the first half faded, to be replaced by greater coverage of Norway's involvement in United Nations High Commissioner for Refugees (UNHCR) programs. While many news pieces addressed global issues such as the plight of Syrian refugees and those in other pockets of unrest and strife throughout the world, the Norwegian press often brought the discussion back to the impact this is having on the numbers of people seeking refuge and asylum in the EU and, by extension, Norway. 
Notwithstanding the uniformity of message-framing at the aggregate level with all migration messaging taken into account, there were differences both between countries and between phases, when specific themes were analysed. As shown in Figure 11.10, the framing of media messages on 'immigration and immigrants' appeared to be quite different in the six very high HD countries. Australia and Canada were the only countries that had messaging framed in a security context, although Australia's messaging was predominantly framed in a sociocultural context (60 per cent) and Canada's was framed mainly in a humanitarian context (61 per cent).

Economic framing was still high in Switzerland, although this had come down since Phase I-a reduction in economic framing of this theme was experienced across all six countries to a greater or lesser degree but most noticeably in the UK (79 to 38 per cent). While this reduction may be related to a postelection period of 'normalisation', it is interesting that the economic framing of this theme reduced across all countries. It may be that solid economic growth and a greater sense of economic stability is underpinning the change in these countries. It may also be possible that messaging related to 'immigration and immigrants' was affected by the substantial increase in the humanitarian framing of the 'asylum seekers and refugees' theme.

In the Netherlands ...

'Asylum seekers and refugees' was the most prominent theme during the study periods. There was an increase in unfavourable commentary in Phase II. This was driven by discussion of contentious issues, including the need for a 'rejection quota' for unsuccessful asylum seekers and limits on the extent to which asylum seekers should have access to health care. There was also a greater focus on asylum seeker processing and deportation in the second phase, which again served to increase the proportion of unfavourable messaging on asylum seekers and refugees. News of the arrival of asylum seekers from Eritrea and Syria also fed into these discussions.

Australia—which experienced a relatively small proportional coverage of the theme 'immigration and immigrants' in both phases_-had a discussion on the topic that was more likely to have been framed in the sociocultural and security contexts compared with the other countries. This would appear to be related to the messaging in print and online media on the integration of Muslim migrants in Australia, a topic that appeared to be dominated by unfavourable messaging. 


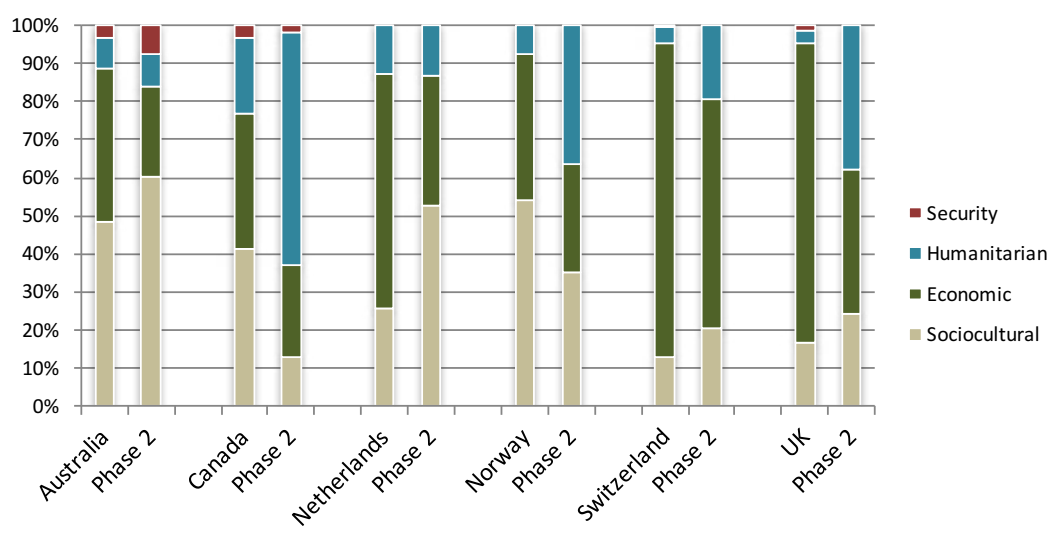

Figure 11.9: Framing of migration messages in print and online media in selected very high HD countries-immigration and immigrants theme: Phase I and II

Notes: Messages: Australia ( $n=2,185)$, Canada $(n=4,738)$, Netherlands $(n=1,488)$, Norway $(n=813)$, Switzerland $(n=2,630)$, UK $(n=9,440)$.

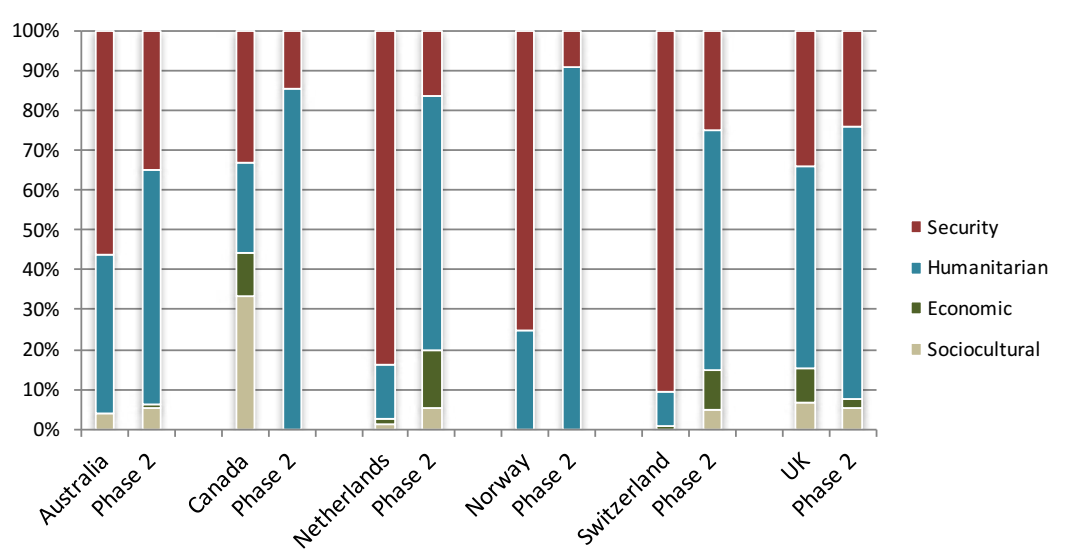

Figure 11.10: Framing of migration messages in print and online media in selected very high HD countries-irregular migration theme: Phase I and II

Notes: Messages: Australia $(n=7,908)$, Canada $(n=166)$, Netherlands $(n=2,548)$, Norway $(n=269)$, Switzerland $(n=2,498)$, UK $(n=3,825)$.

As shown in Figure 11.10, a very different picture emerges of reporting of the theme 'irregular migration', with the framing of media messaging in Switzerland, Norway and the Netherlands having shifted from a predominantly security-related framing to a humanitarian framing, and bringing them more in line with the UK. The security framing of the Phase 
I messaging appeared to have been related to discussion of border security within Europe and irregular maritime migration across the Mediterranean Sea, from North Africa in particular. It is difficult to fully account for the evening-out of the message contexts, which now appear to be much more consistent across all countries. As with other themes, Australia's messaging had a slightly higher proportion framed in a security context.

Analysis of the 'asylum seekers and refugees' theme shows that the messaging was predominantly framed in the humanitarian context, although all three contexts were present in all countries. Norway saw a slight shift in framing of the theme, with an increase in 'economic' framing, while Australia's sociocultural framing in Phase I dropped markedly to become similar to levels in the other countries.

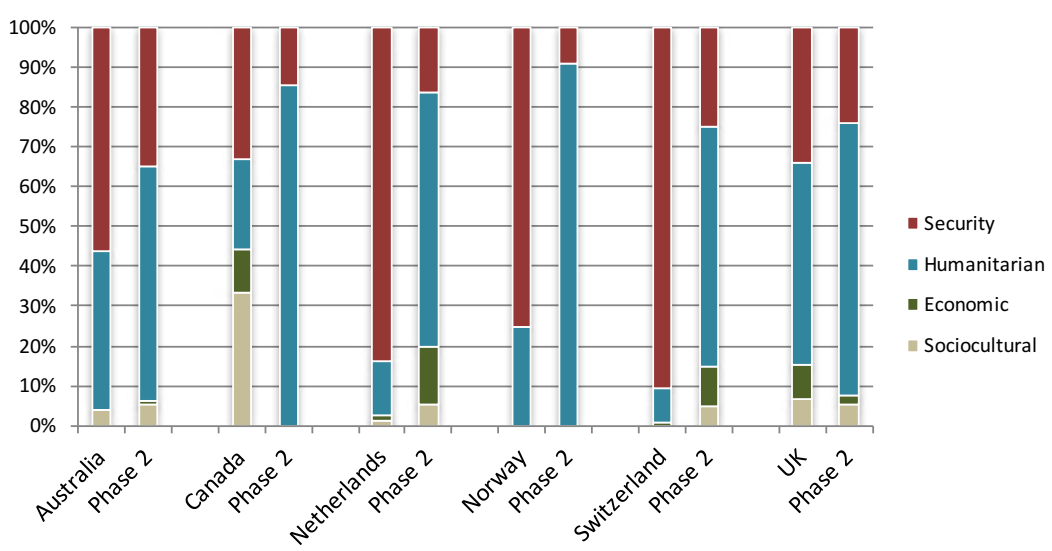

Figure 11.11: Framing of migration messages in print and online media in selected very high HD countries-asylum seekers and refugees theme: Phase I and II

Notes: Messages: Australia $(n=4,679)$, Canada $(n=2,854)$, Netherlands $(n=5,803)$, Norway $(n=1,970)$, Switzerland $(n=4,620)$, UK $(n=2,795)$.

\section{Key findings and differences between other HD countries}

There has been very little research on the media coverage of migration issues in countries that are not the very high HD migration destination or receiving countries. Countries that have been rated as having lower $\mathrm{HD}$, but particularly those with low HD, have not tended to have been included in research on this topic. As discussed in McAuliffe and Weeks 
(2015), there would appear to be several reasons for this. First, it can be very difficult to access and collect media articles from some countries. Second, the need for multilingual analysts with native language skills and an appreciation of current social and cultural environments poses challenges. Third, and particularly in relation to comparative analysis, ensuring consistency across different country analyses can be difficult.

This project attempts to fill some of this research gap. In doing so, and taking into account the findings of Phase I, the seven 'other' HD countries have been grouped to facilitate comparative analysis: Afghanistan (low HD), Bangladesh (medium HD), Malaysia (high HD), Pakistan (low HD), Sri Lanka (high HD), Thailand (high HD) and Vietnam (medium HD). We have moved away from categorising the countries in scope as 'origin' countries.

The key findings rely on smaller country-specific datasets compared with those compiled for very high HD countries. This was partly related to significant differences in media volumes and to difficulties with collection. Nevertheless, a comparative analysis produced some interesting findings:

- Consistent with Phase I findings, there remains a diversity of coverage by theme as well as tone and context across the seven other HD countries.

- The inclusion of Malaysia and Thailand highlighted the very different volumes of media, with Malaysia's volume being very high, which is likely to be related to infrastructure and access, but also to the nature of the topics covered in those countries-Malaysia and Thailand's coverage tended to reflect their status as migration 'receiving' countries.

- Taking into account all print and online messages on migration and migrants in the other HD countries, ${ }^{4}$ it is evident that there was a small but noticeable shift in message tone between Phases I and II, toward a more balanced coverage overall. While neutral coverage decreased slightly, favourable messages increased and unfavourable coverage decreased marginally.

4 Involved analysis of more than 28,000 individual messages from 6,000 articles reported between 1 October 2013 and 30 September 2014 in Afghanistan, Bangladesh, Malaysia, Pakistan, Sri Lanka, Thailand and Vietnam. 
- Overall, coverage of migration in print and online media tended to be less polarised in other HD countries than in very high HD countries, with more neutral reporting and less unfavourable reporting in origin countries. That said, reporting was more likely to be unfavourable than favourable, which is consistent with very high HD countries.

- Most media reporting on migration in both phases was framed in a humanitarian context, far outstripping economic, sociocultural and security contexts.

- Perhaps partly due to issues related to press freedom-as discussed above- the focus on migration in print and online media related primarily to the multitude of aspects associated with the rights and treatment of citizens.

- Reporting in a security context was evident in both phases in relation to people smuggling and, to a lesser extent, irregular migration.

\section{Thematic content in print and online media in other HD countries}

All media messages from the country-specific datasets were analysed against a number of themes. As noted in the previous section, a single print or online article may contain more than one message, and each message may relate to more than one theme. Analysing the datasets in this way allows for all messages to be described in thematic terms.

As shown in Figure 11.12, the volume of migration-specific print and online messaging was relatively similar in Phases I and II for all countries except Thailand and Vietnam, which experienced significant increases in the second phase. While the increases may be related to seasonal effects (as discussed above), they are clearly due in part to the heightened coverage of 'irregular migration' in Thailand and 'overseas workers' in Vietnam.

As with the very high HD countries, the volume of migration-related print and online media messaging varied substantially between the two countries. Malaysia's volume is akin to that of Canada and far exceeds all of the other countries in this group - a result that reflects the maturity and size of its media industry, as well as the focus on migration in public discourse. 


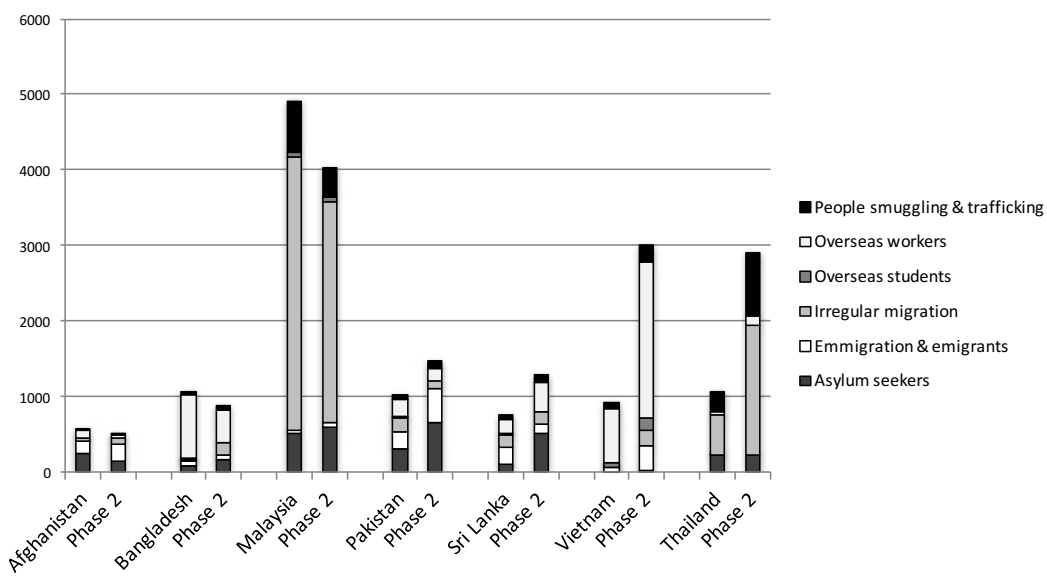

Figure 11.12: Thematic coverage of migration in print and online media in selected other HD countries by volume-key migration themes: Phase I and II

Notes: Messages: Afghanistan $(n=1,100)$, Bangladesh $(n=1,961)$, Malaysia $(n=8,936)$, Pakistan $(n=2,522)$, Sri Lanka $(n=2,041)$, Thailand $(n=3,964)$, Vietnam $(n=3,945)$. Articles: Afghanistan $(n=703)$, Bangladesh $(n=1,027)$, Malaysia $(n=3,716)$, Pakistan $(n=1,654)$, Sri Lanka $(n=1,317)$, Thailand $(n=1,870)$, Vietnam $(n=1,725)$.

In terms of thematic messaging analysed proportionally, and as shown in Figure 11.13, there was considerable variation in the thematic content between the countries. It is likely that the differences between the other HD countries reflect the very different national discussions that occurred during the study periods. Further, the substantial differences, and the nature of some of the thematic messaging, reflect the current state of migration more broadly within each country. Consistent with migration flows from Vietnam and Bangladesh, for example, 'overseas workers' dominated the print and online media messages in both phases. Reporting on Phase I findings noted that the results from Sri Lanka were somewhat at odds with the long history of regular labour migration flows from Sri Lanka; however, Phase II saw this theme become more prominent in Sri Lanka, with a reduction in both 'irregular migration' and 'emigration and emigrants'. 


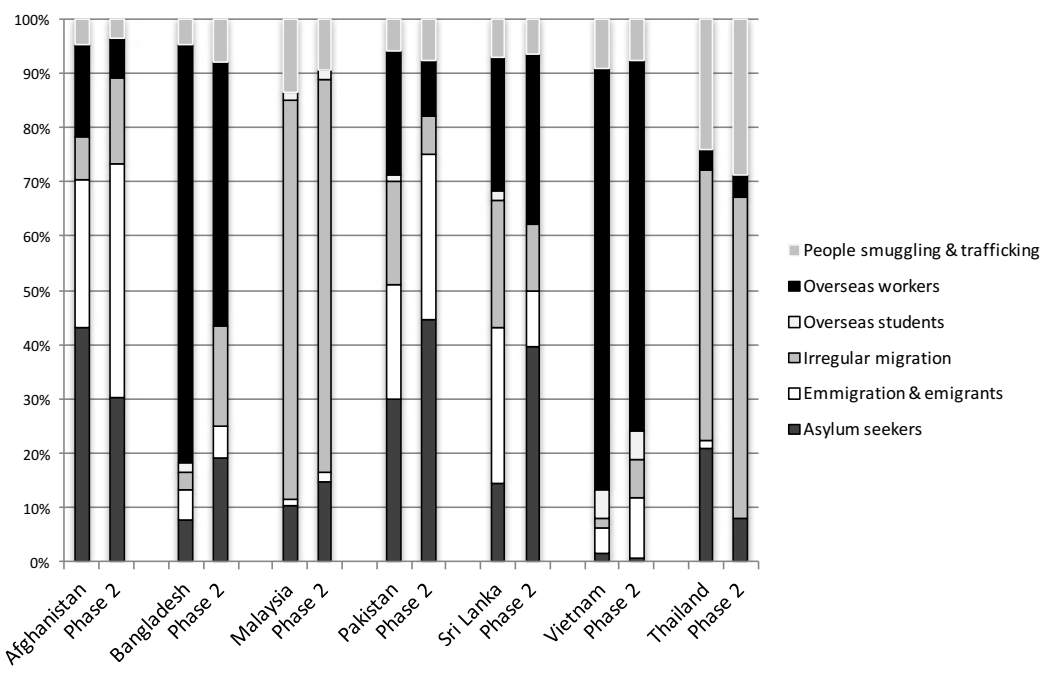

Figure 11.13: Thematic coverage of migration in print and online media in selected other HD countries by proportion-key migration themes: Phase I and II

Notes: Messages: Afghanistan $(n=1,100)$, Bangladesh $(n=1,961)$, Malaysia $(n=8,936)$, Pakistan ( $n=2,522)$, Sri Lanka $(n=2,041)$, Thailand $(n=3,964)$, Vietnam $(n=3,945)$. Articles: Afghanistan $(n=703)$, Bangladesh $(n=1,027)$, Malaysia $(n=3,716)$, Pakistan $(n=1,654)$, Sri Lanka $(n=1,317)$, Thailand $(n=1,870)$, Vietnam $(n=1,725)$.

It is interesting to note the dominance of the media messaging on 'irregular migration' in Malaysia and Thailand, which is far greater proportionally than any of the other countries, including the very high HD countries. This appears to reflect the current migration issues facing those countries. In Malaysia, for example, there are estimated to be up to two million irregular migrants residing in the country, many working in the unregulated economy (McAuliffe \& Mence, 2014). In Thailand, the very high proportional messaging on 'irregular migration' was related mainly to the Thai Government's crackdown of illegal migrant workers from Cambodia, Myanmar and Laos in early 2014, which preceded its migrant worker registration scheme (from June 2014). The scheme was reported as resulting in the registration and legalisation of more than one million former illegal migrants.

The amount of messaging on 'asylum seekers and refugees' increased in the majority of countries in Phase II, with slight reductions experienced in only Afghanistan and Thailand. Unlike coverage of this theme in very high HD countries, examination of the articles related to 'asylum seekers 
and refugees' indicates that these tend to be on local issues rather than the more general material on refugee crisis situations (e.g. Syria) and Mediterranean Sea asylum seeker movements. For example, in Pakistan the focus was on Afghan refugees and repatriation, while in Sri Lanka the discussion revolved around Pakistani asylum seekers in Sri Lanka as well as on Sri Lankan asylum seekers attempting to reach Australia. Bangladesh, on the other hand, witnessed a discussion on this theme that was dominated by Rohingya-related issues.

In Sri Lanka ...

Throughout the year-long study period, the Sri Lankan print and online media showed substantial interest in those citizens choosing to leave Sri Lanka. It explored these departures from a number of different perspectives. The message theme of 'asylum seekers and refugees' often dealt not just with those entering Sri Lanka, but also with Sri Lankans seeking refuge outside the country. 'Emigration and emigrants' addressed the matter of citizens leaving through proper channels, while 'irregular migration' messages related to both irregular arrivals into Sri Lanka, and, to some extent, news of citizens accused of irregularly migrating to other countries.

\section{Extent of polarisation of print and online media content in other HD countries}

Consistent with the findings for very high $\mathrm{HD}$ countries, when all messages related to migration and migrants are aggregated across all other HD countries, it is evident that there was a small but noticeable positive shift between Phases I and II toward more balanced coverage overall. Overall, and as can be seen from Figure 11.14, favourable coverage increased (from 11 per cent to 17 per cent), while unfavourable coverage decreased (from 49 per cent to 46 per cent), as did neutral coverage (39 per cent to 36 per cent). It would appear that no specific events or circumstances drove this change-it is more likely that a combination of changes in overall message volume in some countries, together with variations in thematic content, appear to have overall had a combined effect. It will be interesting to examine this high-level indicator in future phases, particularly as it tends to blunt the more event-based changes, and has the ability to provide a useful overall barometer on print and online media coverage of migration and migrants. This summary result is based on analysis of over 28,000 individual messages from more than 6,000 articles. 


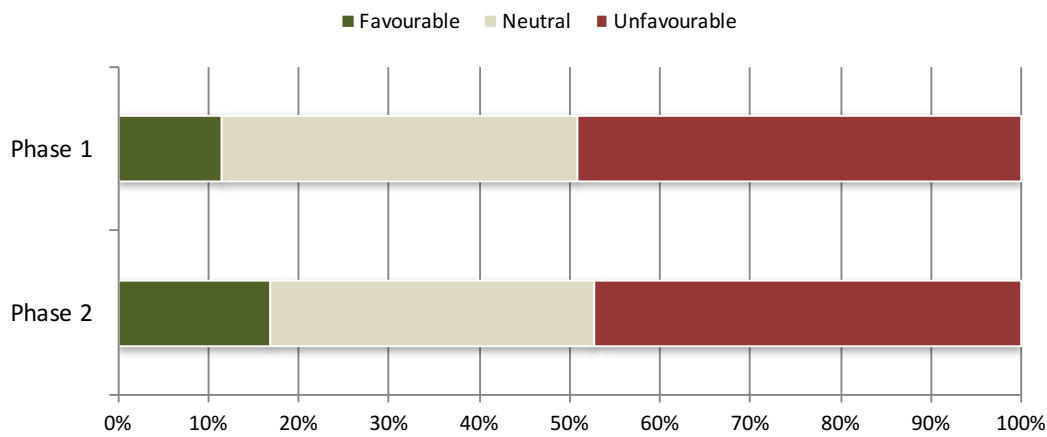

Figure 11.14: Favourable-neutral-unfavourable coverage of migration in print and online media in selected other HD countries combinedall migration themes: Phase I and II

Notes: Messages: Phase $1(n=12,040)$, Phase II $(n=16,349)$. Articles: Phase $1(n=6,035)$, Phase II $(n=8,010)$.

In Thailand ...

The 'immigration and immigrants' theme generated the highest level of favourable messages, with commentary pointing to the economic benefits (legitimate) foreign workers bring to the country. Unfavourable messages relating to this theme appeared more in a sociocultural context, with reports suggesting links between immigrants and criminal activity.

The 'asylum seekers and refugee' theme was another in which Thailand's media was similar to its neighbour, Malaysia. Media in each country focused on the plight of Rohingya refugees, while also presenting news relating to the Australian Government's asylum seeker policy. Favourable messages were driven by support for the plight of Rohingya living in Thailand, while unfavourable messages highlighted the difficulties faced by asylum seekers suffering with deportation or detention.

While not overly prominent in terms of absolute message numbers, the 'overseas workers' theme attracted a reasonably high level of favourable commentary (33 per cent). Government support of Thai workers was a leading positive message, while unfavourable commentary ( 25 per cent) appeared largely in connection with stories about the hardships faced by Thai workers, internationally.

As was the case with very high HD countries, the research found considerable variability in the tone of the media coverage of migration between other HD countries. Figure 11.15 shows that higher proportions of unfavourable messaging were experienced in all countries except Malaysia and Thailand, which remained at high levels. Malaysia experienced the highest levels of unfavourable messaging (57 per cent) and the lowest levels of favourable (10 per cent), very closely echoing the results for Australia (49 per cent unfavourable; 13 per cent favourable). 


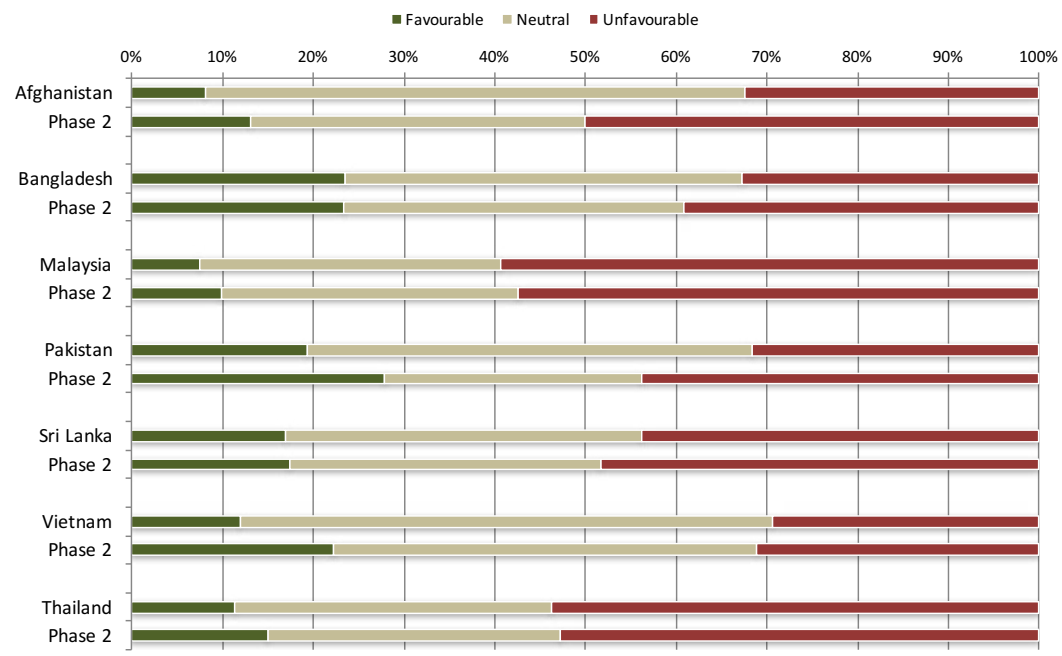

Figure 11.15: Favourable-neutral-unfavourable coverage of migration in print and online media in selected other HD countries-key migration themes: Phase I and II

Notes: Messages: Afghanistan $(n=1,124)$, Bangladesh $(n=2,028)$, Malaysia $(n=11,128)$, Pakistan $(n=2,656)$, Sri Lanka $(n=2,142)$, Thailand $(n=4,730)$, Vietnam $(n=4,581)$. Articles: Afghanistan $(n=721)$, Bangladesh $(n=1,070)$, Malaysia $(n=4,804)$, Pakistan $(n=1,766)$, Sri Lanka $(n=1,393)$, Thailand $(n=2,338)$, Vietnam $(n=1,953)$.

The proportions of neutral media coverage between the two phases dropped in all countries except Malaysia, where it remained the same. The print and online messaging in Afghanistan and Pakistan became noticeably more polarised in the second phase, with both unfavourable and favourable messaging increasing. This was in a context of otherwise fairly consistent results between the two phases and across almost all countries.

Not surprisingly, the two countries with the highest proportional and actual messaging on irregular migration (Malaysia and Thailand) experienced the highest proportions of unfavourable messaging and low levels of favourable, when all themes are taken into account. These results accord with the findings for Australia, which shared these key characteristics related to thematic messaging and the tone of the overall messaging. In all three countries, there would seem to be an emphasis on linking irregular migration to the success or otherwise of government policy and practice in managing immigration. 
In Pakistan ...

The 'asylum seekers and refugees' theme accounted a third of all messages, and was the most prominent issue across the entire study period. While overall unfavourable messages still outnumbered favourable ones, the second phase of the study saw an improvement in tone with the announcement of monetary aid from foreign nations, including the US and Japan, and support from the UN. Pakistan was also praised for the magnanimity with which it receives refugees.

Unfavourable messages related to the suffering of refugees in the country's camps and their inadequate accommodation. We also saw significant frustration expressed about the level of ongoing support needed for refugees, and, concurrently, concerns about potential links between terrorists and refugees, while the large economic and social burden placed on countries hosting refugees was also noted.

As shown in Figure 11.16, the theme 'overseas workers' received a reasonable amount of favourable media coverage in most origin countries during the study period, with a significant increase having occurred in Pakistan. Consistent with the findings for Phase I, the two countries in which the theme dominated (Bangladesh and Vietnam) did not have the highest proportions of favourable coverage, although they both increased in Phase II. One of the starker findings is that all countries experienced polarisation of messaging on this theme-lower levels or much lower levels of neutral reporting occurred in Phase II.

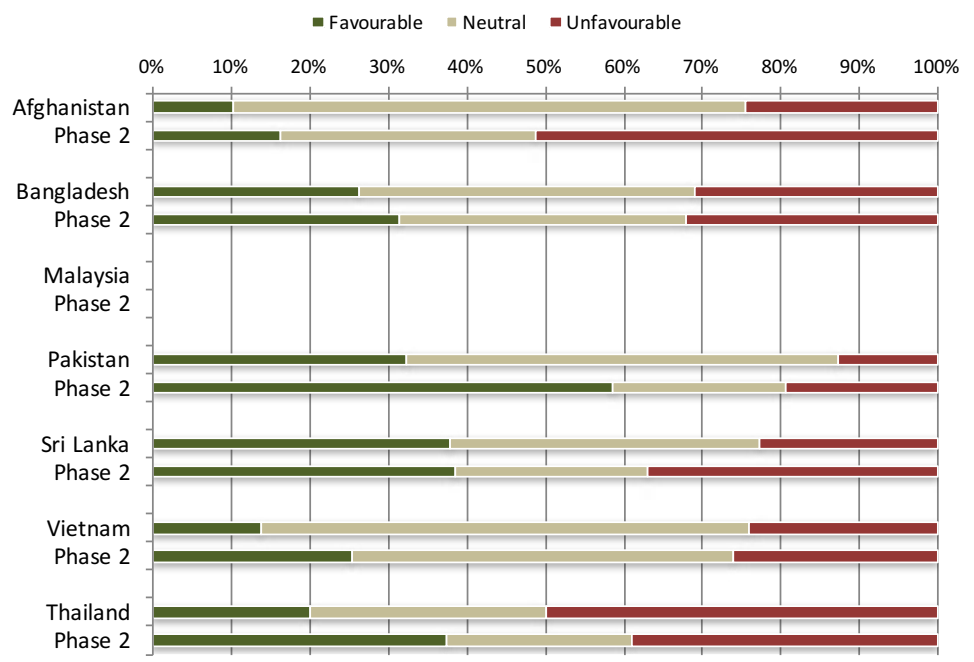

Figure 11.16: Favourable-neutral-unfavourable coverage of migration in print and online media in selected other HD countries-overseas workers theme: Phase I and II

Notes: Messages: Afghanistan ( $n=135)$, Bangladesh $(n=1,257)$, Malaysia $(n=8)$, Pakistan $(n=390)$, Sri Lanka $(n=585)$, Thailand $(n=158)$, Vietnam $(n=2,785)$. Articles: Afghanistan $(n=89)$, Bangladesh $(n=589)$, Malaysia $(n=8)$, Pakistan $(n=276)$, Sri Lanka $(n=314)$, Thailand $(n=74)$, Vietnam $(n=1,074)$. 
In Bangladesh ...

Print and online media was highly focused on the 'overseas workers' theme, typically addressing the hardships confronting these people. Over half of all messages reported during the one-year study period were on this theme. The prominence of stories and messages on the plight of overseas workers aligned with the often-reported link between the health of the Bangladeshi economy and the remittances flowing from its foreign workers.

A long way back in terms of its prominence was the second-most reported theme of 'asylum seekers and refugees' (15 per cent). The standout issue discussed here was Rohingya refugees in Bangladesh and Myanmar, which became more prominent in Phase II.

In contrast to the tone of the media messaging on 'overseas workers', the coverage of 'irregular migration' was once again extremely unfavourable, although there were some changes evident in Pakistan and Vietnam. As was found in Phase I, the tone of the coverage of this theme was the second most unfavourable of all of the thematic coverage across all very high HD and other HD country datasets—second only to 'people smuggling and trafficking', which received extremely unfavourable commentary in all countries.

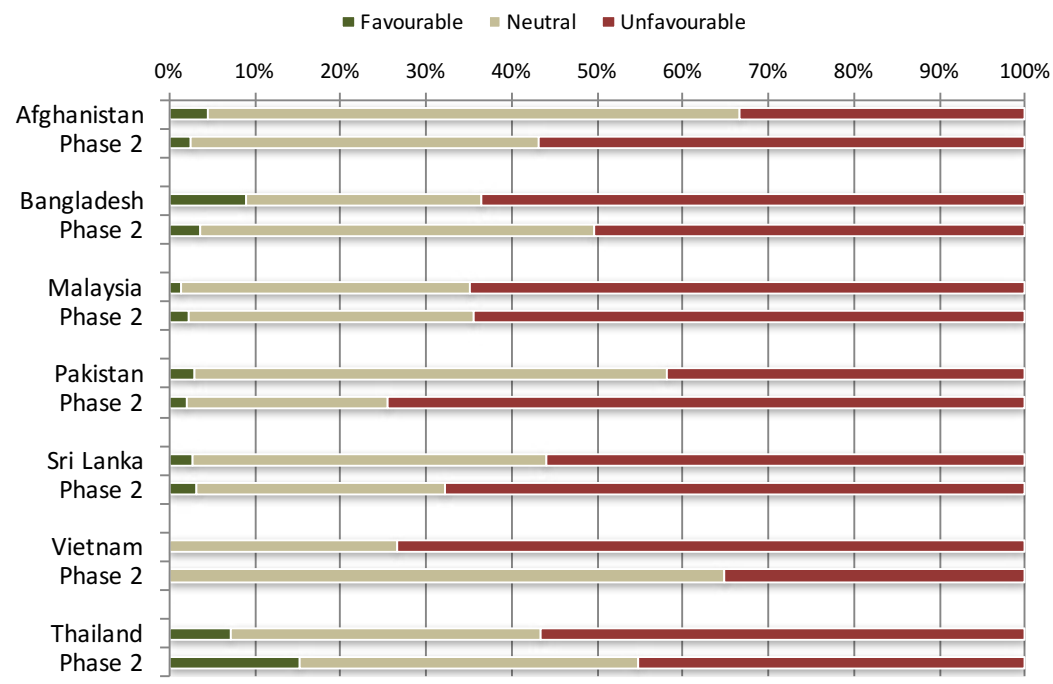

Figure 11.17: Favourable-neutral-unfavourable coverage of migration in print and online media in selected other HD countries-irregular migration theme: Phases I and II

Notes: Messages: Afghanistan $(n=126)$, Bangladesh $(n=205)$, Malaysia $(n=6,516)$, Pakistan $(n=298)$, Sri Lanka $(n=338)$, Thailand $(n=2,234)$, Vietnam $(n=225)$. Articles: Afghanistan $(n=83)$, Bangladesh $(n=129)$, Malaysia $(n=2,544)$, Pakistan $(n=220)$, Sri Lanka $(n=227)$, Thailand ( $n=992)$, Vietnam $(n=126)$. 
Interestingly, the tone of the messaging on irregular migration in other HD countries tended to be much more unfavourable (35 per cent to 75 per cent) compared with very high HD countries. This reflected the focus on the dangers to potential irregular migrants, deportations of irregular migrants back to the other HD country as well as commentary on the dangers posed by irregular migrants from elsewhere. It should be noted, however, that the volume of messaging on 'irregular migration' was reasonably low, with only Malaysia and Thailand experiencing substantial volumes (see Figure 11.12).

\begin{abstract}
In Vietnam ...
Print and online media on migration issues in Vietnam was similar in many respects to that of other countries ranked lower on the HDI. It had a strong focus on the opportunities and challenges faced by citizens working in foreign countries, and the valuable contribution these workers make to the Vietnamese economy through the flow of remittances. Discussion surrounding inbound migration in the Vietnamese press was limited and was largely driven by specific events.

This event-driven media surrounding inbound migration produced something of shift when comparing the two phases in this study period. In the first phase of the study, press articles relating to 'overseas workers' made up the lion's share of coverage (68 per cent), while coverage relevant to 'immigration and immigrants' was insignificant. In the second phase, tensions caused by the development of a Chinese oil rig in Vietnamese waters led to anti-China protests that targeted industrial zones housing large numbers of Chinese workers. The subsequent media interest in these events saw the 'immigration and immigrants' theme jump to a 15 per cent share of coverage across the April-September 2014 period.
\end{abstract}

\title{
Framing of the media discourse in other HD countries
}

The first striking result of the research is the dominance of the 'humanitarian' framing in all other HD countries across both phases. Messaging on migration and migrants in print and online media coverage is being predominantly depicted through a 'humanitarian' lens. Other framing is present and in some countries not insubstantial-24 per cent 'security' in Malaysia, 25 per cent 'economic' in Bangladesh-but all countries' messaging is predominantly framed in a 'humanitarian' context, regardless of the differences in substance and complexity of national migration issues.

The second key finding is the noticeable degree of uniformity between the two phases. All countries experienced similar results in the two phases, with moderate changes largely being limited to increases in 'humanitarian' framing in Afghanistan, Pakistan and Sri Lanka (with concomitant 
decreases largely in 'sociocultural' framing). While it is difficult to anticipate the results of future phases, it would be useful to have this trend finding confirmed (or otherwise) through further research.

In Malaysia ...

The Malaysian press was most focused on the inflow of immigrants, with the most prominent area of discussion being 'irregular migration'. This theme accounted for 53 per cent of the messages studied across the 12-month study period, and its significance in the study set points to the high importance of this issue to the Malaysian nation. Very large numbers of people enter the country to work each year, and the management of this human flow was shown through the media to be a daunting task for policymakers and administrators alike.

With two thirds of 'irregular migration' messages being critical of people entering Malaysia through unlawful channels, and half of all messages unsupportive of legal 'immigration and immigrants', it's no surprise that the most prominent themes were represented in a largely unfavourable tone.

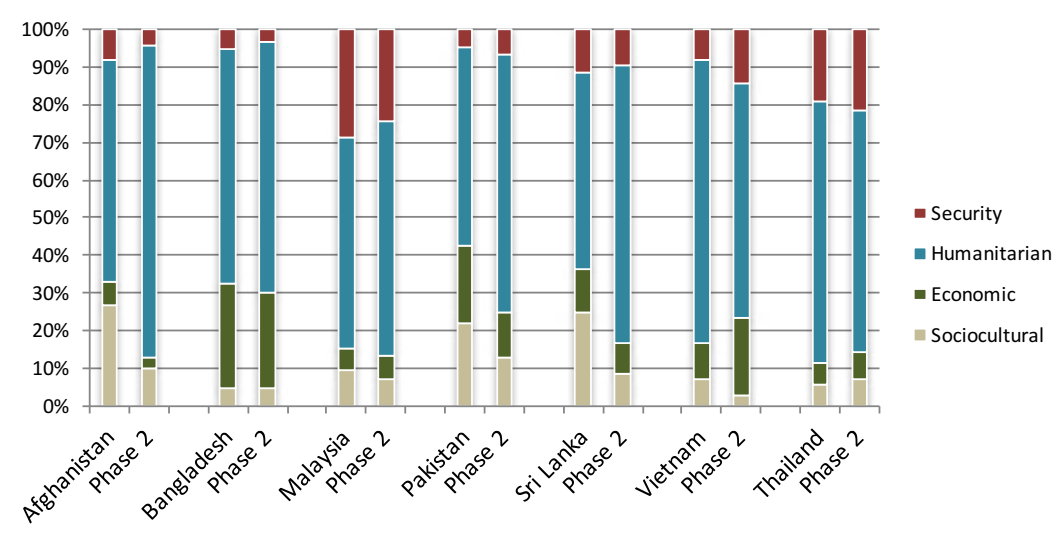

Figure 11.18: Framing of migration messages in print and online media in selected other HD countries-all migration themes: Phases I and II

Messages: Afghanistan $(n=1,018)$, Bangladesh $(n=1,995)$, Malaysia $(n=11,128)$, Pakistan $(n=2,612)$, Sri Lanka $(n=1,603)$, Thailand $(n=4,730)$, Vietnam $(n=4,497)$.

The two countries that experienced the highest proportions of 'security' framing (Malaysia and Thailand) have arguably the highest numbers of irregular labour migrants who are not asylum seekers or refugees in their communities (International Federation for Human Rights [FIDH] \& Suara Rakyat Malaysia [Suaram], 2008; IOM, 2011b). While acknowledging that this is difficult to state categorically, given the lack of hard data on migrant flows and stocks, the little we do know seems to be consistent with the overall results. 
Consistent with Phase I, the discussion of 'overseas workers' was more likely to have been framed in an economic context compared with the overall migration discussion, with an exception being Thailand. In Thailand, there was not much coverage of this theme either in volume or proportional terms, but the little that was reported was framed in a humanitarian context, indicating perhaps less of a reliance on remittances in this country.

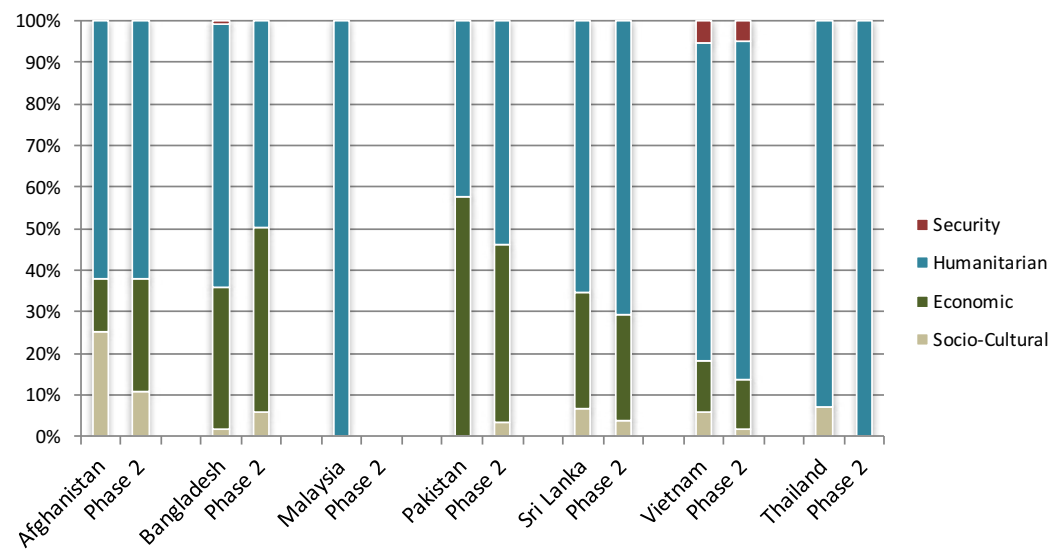

Figure 11.19: Framing of migration messages in print and online media in selected other HD countries - overseas workers theme: Phases I and II Messages: Afghanistan $(n=138)$, Bangladesh $(n=1,255)$, Malaysia $(n=8)$, Pakistan $(n=424)$, Sri Lanka $(n=414)$, Thailand $(n=158)$, Vietnam $(n=2,718)$.

In other HD countries, as was the case in very high HD countries, discussion on 'irregular migration' saw a greater proportion of messages framed in a security context, with little or no economic framing. While there was uniformity across the two phases for most countries, Vietnam was an exception: security framing jumped from 23 per cent in Phase I to 96 per cent in Phase II. There appear to be two main reasons for this. First, the volume of messaging in Vietnam in both phases was small. Second, the coverage was mainly associated with event-driven reporting of Chinese irregular labour migrants and security-related incidents (including shootings) and threats. 


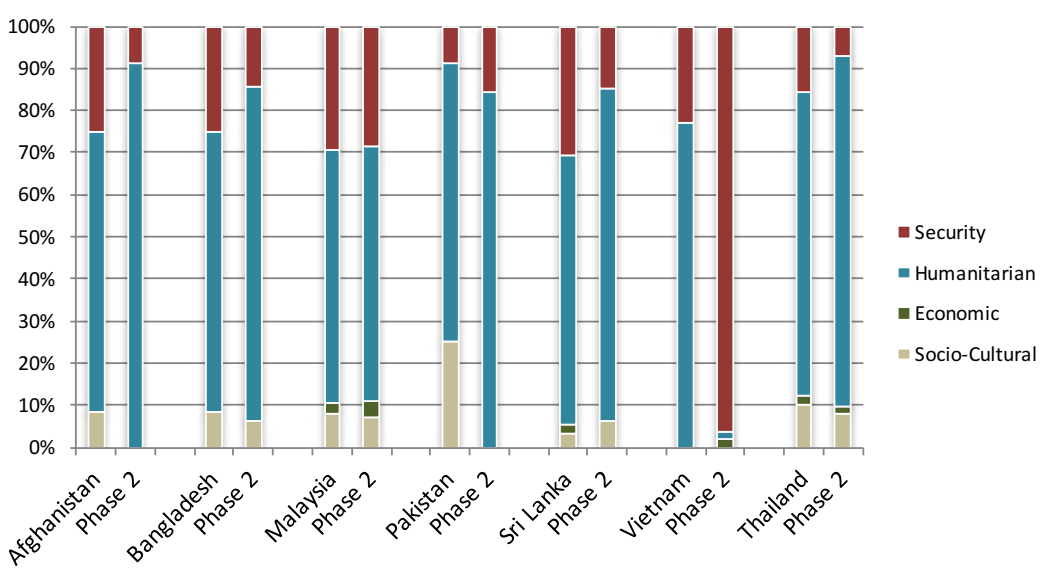

Figure 11.20: Framing of migration messages in print and online media in selected other HD countries-irregular migration theme: Phases I and II Messages: Afghanistan $(n=112)$, Bangladesh $(n=201)$, Malaysia $(n=6,516)$, Pakistan $(n=284)$, Sri Lanka $(n=243)$, Thailand $(n=2,234)$, Vietnam $(n=226)$.

\section{Implications for policymakers}

The media is often accused of generalising-usually negativelyabout migrants and migration, for example by scaling up individual misdemeanours to entire populations, or failing to tell good news as well as bad news stories. One of the implications of the preceding analysis is that those who criticise the media in this way are in turn generalising. It is clear that media coverage of migrants and migration is dynamic and quite sophisticated, and varies significantly between countries as well as within countries over time. This noted, a number of initial implications for policymakers can be suggested from this research.

First, and given the significance of media coverage on migrants and migration noted in the Introduction, it is important to promote a fair and reasonable portrayal of migrants in the media, and as this analysis has illustrated this is often still not the case. At a national level, promoting and protecting the freedom of the press is paramount. At the corporate level, there are implications, for example concerning safeguarding editorial independence from commercial interests. At the level of individual media outlets, providing internship or employment opportunities for journalists with a migrant background has been suggested as one way to increase 
a better understanding and more objective coverage of this and indeed other cross-cultural issues. There are powerful reasons to support these sorts of policies beyond just potential migration outcomes.

A second policy area that can be informed by this and subsequent analysis is the design and dissemination of information on migration policies and programs to settled migrants as much as to potential migrants. It is likely that media content and comment has more influence on migrant decisions than many official sources of information, for example because the former may be more trusted and more easily accessible. Understanding how the media shapes its coverage of migration, as this analysis has begun to, has important implications for trying to predict and perhaps direct its influence.

In this regard, one of the key contributions made by the research is the application of a consistent methodology to a selected number of countries to develop a measurable set of indices, which can be monitored over time. This can be appealing for policymakers, as it offers the opportunity to compare media discourses about migration in other countries, including other HD countries. Detecting changes and shifts over time, in a solid and measurable manner, enables policymakers to consider a range of options, including for communications activities, with the benefit of evidence.

\section{Conclusions}

The purpose of this research has been to compare migration discourses in selected countries by examining thematic content, contextual framing, and the extent of polarisation of messages communicated via print and online media over two six-month periods. It is the second phase of a research collaboration between the Department of Immigration and Border Protection and Cubit Media Research, designed to inform migration policymakers and practitioners by drawing on expertise built up in the private sector on large-scale quantitative media analytics.

This project involved large-scale quantitative research that relied on a combination of multilingual human analyses and a human cognitive modelling software system. This developed a unique evidence-base, albeit covering two finite periods and with certain limitations. The research has highlighted, with a reasonable level of confidence, the nature of the migration discussions occurring within the media in the selected countries, as well as the relative 'space' devoted to different migration topics. 
Overall, the evidence this research provides adds to the existing body of work on migration and the media. However, it could be argued that a more pressing longer-term benefit will only be realised through analyses of trends stemming from additional research phases. Discerning changes over time has the potential to uncover trends that are likely to have implications for policymakers and migration practitioners internationally.

\section{Reference list}

Castles, S., de Haas, H., \& Miller, M. (2014). The age of migration: International population movements in the modern world (5th ed.). Hampshire: Palgrave Macmillan.

Erdal, I. J. (2009). Repurposing of content multi-platform news production. Journalism Practice, 3(2), 178-95. doi.org/10.1080/ 17512780802681223

International Federation for Human Rights, \& Suara Rakyat Malaysia. (2008). Undocumented migrants and refugees in Malaysia: Raids, detention and discrimination. Report 489/2. Paris: International Federation for Human Rights. Retrieved from www.fidh.org/IMG/ pdf/MalaisieCONJ489eng.pdf.

International Organization for Migration. (2011a). World Migration Report 2011-Communicating Effectively about Migration. Geneva: Author.

International Organization for Migration. (2011b). Thailand Migration Report 2011 - Migration for Development in Thailand: Overview and Tools for Policymakers. Bangkok: Author.

International Telecommunication Union. (2013). Measuring the Information Society. Geneva: Author.

Kandemir, O. (2012). Human development and international migration. Procedia: Social and Behavioral Sciences, 62, 446-51. doi.org/10.1016/j. sbspro.2012.09.073

Keith, S., Schwalbe, C. B., \& Silcock, B. W. (2010). Comparing war images across media platforms: Methodological challenges. Media, War \& Conflict, 3(1), 87-98. doi.org/10.1177/1750635210353676 
Kohut, A., Wike, R., Bell, J., Horowitz, J. M., Simmons, K., Stokes, B., Poushter, J., Barker, C., \& Gross, E. M. (2012). Social networking popular across the globe: Arab publics most likely to express political views online. Retrieved from Pew Research Centre: www.pewglobal. org/files/2012/12/Pew-Global-Attitudes-Project-Technology-ReportFINAL-December-12-2012.pdf.

Koser, K. (2012, 15 August). Securitizing migration: A good or bad idea? (International Relations and Security Network, Zurich, Interviewers) [audio recording]. Retrieved from www.video.ethz.ch/campus/isn/ e64b372e-c59e-4fbb-a091-6bfe68d9a17f.html.

Koser, K. (2014, 5 June). Cities and the case for migration. Keynote address to the 2014 Cities of Migration Conference, Berlin.

McAuliffe, M., \& Mence, V. (2014). Global irregular maritime migration: Current and future challenges. Irregular Migration Research Program, occasional paper series 05. Canberra: Australian Department of Immigration and Border Protection. Retrieved from www.border. gov.au/ReportsandPublications/Documents/research/global-irregularmaritime-migration.pdf.

McAuliffe, M., \& Weeks, W. (2015). Media and migration: Comparative analysis of print and online media reporting on migrants and migration in selected origin and destination countries. Irregular Migration Research Program, occasional paper series 13. Canberra: Australian Department of Immigration and Border Protection. Retrieved from www.border.gov. au/ReportsandPublications/Documents/research/media-migration.pdf.

Quandt, T., \& Singer, J. B. (2009). Convergence and cross-platform content production. In Wahl-Jorgensen, K., \& Hanitzsch, T. (Eds), The Handbook for Journalism Studies (pp. 130-44). New York: Free Press.

Reporters Without Borders. (2014). World Press Freedom Index 2014. Retrieved from rsf.org/en/world-press-freedom-index-2014.

Semetko, H. A., \& Valkenburg, P. M. (2000). Framing European politics: A content analysis of press and television news. Journal of Communication, 50(2), 93-109. doi.org/10.1111/j.1460-2466.2000. tb02843.x

United Nations Development Programme. (2014). Human development report 2014. Geneva: Author. Retrieved from hdr.undp.org/en/2014report. 
This text is taken from A Long Way to Go: Irregular Migration Patterns, Processes, Drivers and Decision-making, edited by Marie McAuliffe and Khalid Koser, published 2017 by ANU Press, The Australian National University, Canberra, Australia.

dx.doi.org/10.22459/LWG.12.2017.11 